\title{
sciendo
}

\section{An explorative study of tourism time series: Evidence from Slovenia and Croatia}

\author{
Sergej Gričar \\ University of Novo mesto Faculty of Economics and Informatics, Slovenia \\ sergej.gricar@gmail.com
}

Tea Baldigara

University of Rijeka, Faculty of Tourism and Hospitality Management, Croatia

teab@fthm.hr

\begin{abstract}
This paper investigates the long-term cointegration between tourism prices and domestic inflation in Croatia and Slovenia. Those two countries share a common economic history and statistical crispness in the 20th century, the time when Econometrics was not a blossoming topic. The two countries split the common economic path in the 1990s and since then, econometricians have been tackling different development issues and researches. The purpose of the paper is to stress the importance of using a well-designed time-series methodology when dealing with multiple variables estimation and evaluation as well in designing adequate and efficient quantitative models, capable to provide valuable forecasts and predict external shocks. It is assumed that, at the basis of an efficient quantitative model, there is a need of unit root and errors normal distribution testing. To test the covariance of cointegration between tourism prices and domestic inflation, the vector autoregressive model (VAR) model is used on 260 valid monthly time-series observations ( 22 years). The results have shown that prices of short-stay accommodation in Slovenia are cointegrated with domestic inflation, whereas in Croatia there is no stable cointegration vector on prices of accommodation services if / when analysed using the intervention dummy variables and a constant. Although the results indicate that the research hypothesis is generally confirmed, better and more robust results could be obtained including mean-shift dummy variables in a VAR model.
\end{abstract}

Keywords: Croatia, Slovenia, tourism time-series methodology, VAR models.

JEL classification: C15, C22, Z32.

DOI: 10.2478/crebss-2019-0015

Received: October 03, 2019

Accepted: November 30, 2019

Acknowledgments: This article was written with the financial support of the Slovene Human Resources and Scholarship Fund.

\section{Introduction}

Slovenia and Croatia are Central European countries (CEC) that shared the same political folklore, economic dispersion, statistic division and military paths in the 20th 
Century. After the collapse of former socialistic Yugoslavia, the countries diverged in transition processes and obstacles that made each country different politically, economically, statistically and other policy manners. Those two countries share a common economic history and statistical crispness in the 20th century, where Econometrics was not a blossoming topic. The two countries split the common economic path in the 1990s and since then, econometricians have been challenging different development issues and researches. Slovenia and Croatia are members of the European Union (EU) and are under the United Nations (UN) treatment as developed countries.

The Adriatic region, where Croatia and Slovenia are located, have received a substantial deficit in quantitative scientific research. There are several reasons for this nuance. One is the heterogeneity and non-regularity of available secondary data in long terms.

The aim of this paper is to design a well-defined and accurate vector autoregressive model (VAR) capable of capturing time-series data patterns and examining the existence of potential relationships between different economic sectors in Croatia. Moreover, as argued by Gričar and Bojnec (2019), normalities and unit root testing is omitted and their importance is significantly underestimated in previous papers and analysis. This paper is an attempt to stress the importance of normality and unit root testing in analysing time-series models, as a prerequisite in defining adequate and accurate forecasting models.

The motivation of the paper is to emphasize the importance of analysing error normality and unit root testing as a basis for adequate forecasting model designing. This paper represents an explorative study in which the normality and unit root testing of an empirical model based on the Croatian tourism industry statistical data is compared with the Slovenian overnight stays model defined by Gričar and Bojnec (2019).

The research issue that underpins this paper is to check and define the validity of tourism volatile models on tourism prices and domestic inflation in Croatia and to summon a comparative analysis with previous results obtained by Gričar and Bojnec (2019). In the study, VAR modelling is applied, based on unit root testing and error normality. The aims of the research are to estimate and test empirical time-series data, as well as to validate the proposed research methodology in the tourism industry statistical data.

Consequently, the purpose of this paper is to originate effective and valuable empirical tourism industry testing based on econometric inference. For this purpose, four specific objectives have been defined. The first objective is reflected in measuring specific data and implementing a particular methodology, specifically designed for time-series estimation and evaluation. The second objective reflects in the discussion and analysis of the empirical data set. The third objective is the attempt to design and perform the selected quantitative methods suitable for time-series modelling, whilst the last objective is expressed through achieving empirical testing robustness.

Based on previous empirical results, the objectives of the study, two research hypotheses are defined as follows:

$\mathrm{H}_{1}$ : Tourism prices are integrated of a specific order, mostly nearly a second order of integration, and therefore the deflation with national consumer price indices is needed.

$\mathrm{H}_{2}$ : Prices of specific tourism sub-industries (e.g. lodging) are in connection with other global shocks, such as EU or Eurozone tourism prices. 
The next section gives an outline of the literature review and previous empirical researches. In the third section, data and methodology are implemented, following empirical results and discussion.

\section{Literature review}

In Croatia and Slovenia, former socialist Yugoslav republics, gross domestic product (GDP) and tourist arrivals stagnated in the 1990s due to serious structural problems and political instability in the region (Gričar et al., 2019). Simultaneously, the overall prices (inflation) and tourism sub-industry prices in the region grew considerably (Gričar et al., 2018).

In both countries, tourism is now one of the most important economic development generator (Croatian Bureau of Statistics, 2019, Statistical Office of Republic of Slovenia, 2019). A common feature of both countries tourism sector is their strong seasonal pattern (Figure 1) when analysing, modelling and forecasting tourism key determinants.

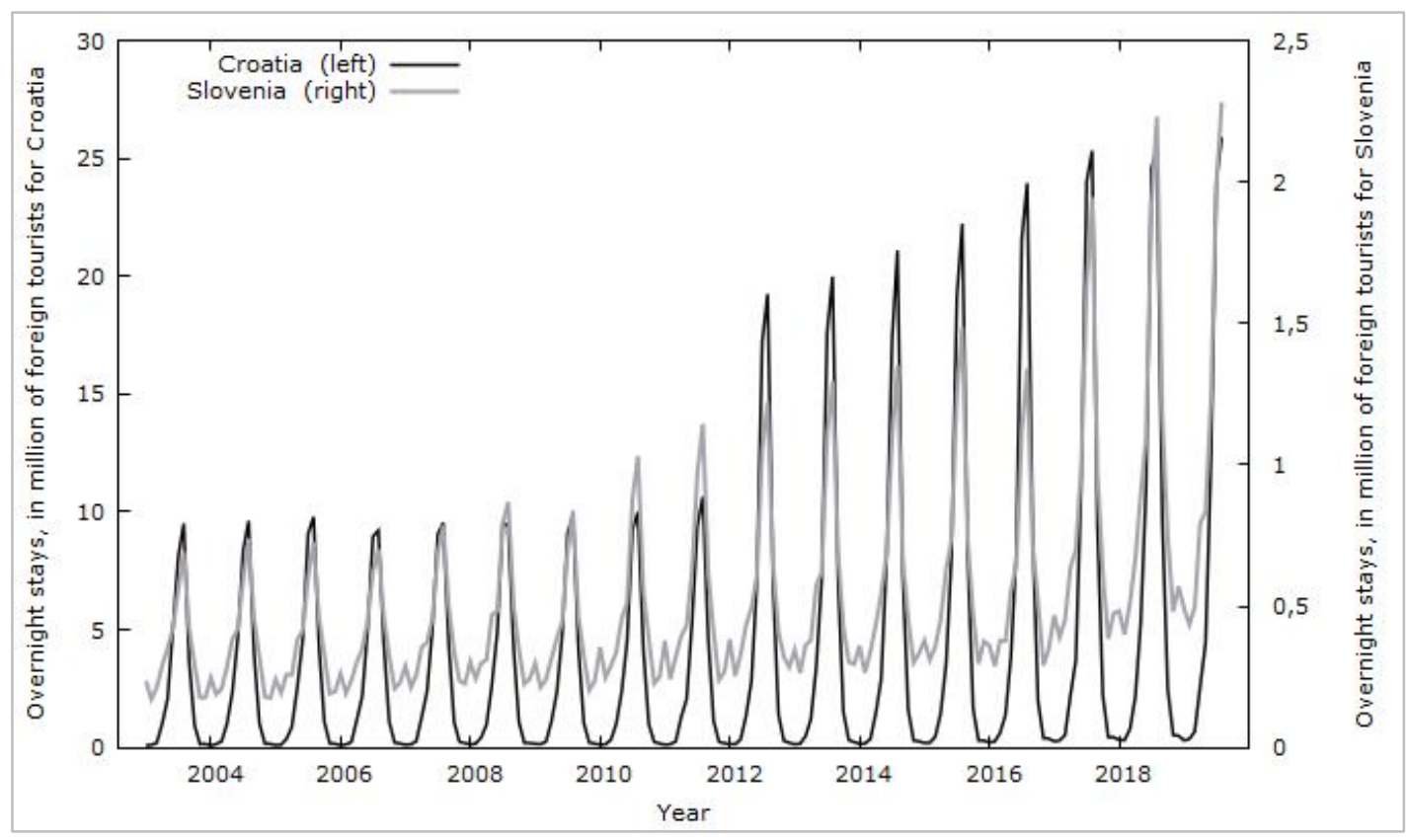

Figure 1 Overnight stays monthly data from January 2003 to September 2019 Source: Eurostat, 2019; author's calculations.

As depicted in Figure 1, the tourist overnight stays time-series of both countries present strong seasonal character and a significant upward trend. It is clear that volatile patterns are unpredictable for the data vector in both countries. The number of tourist overnight stays is at the maximum level in the summer period between July and August, with a sizable fall in the period between October and April. In analysing and modelling tourism time-series, it is important to consider their seasonal character and adopt adequate approaches suitable for dealing with seasonality recently discussed by Senbeto and Hon (2019).

\section{Developed countries}

At this juncture (e.g. 2019), several separate data sources report the evaluation for Slovenian and Croatian incorporation to be developed countries. Meaning that some of the sources still include Croatia as a developing country whereas other sources include Croatia as a developed country alongside Slovenia as a north neighbouring 
country. The positioning of Croatia in the group of developed or developing countries is crucial when deliberating about relevant data source availability, at national statistical offices (Mukherjee et al., 1998). Valuable statistical and administrative data are crucial in the econometric analysis (Atkinson, Brandolini, 2001, Hand, 2018).

United Nations (2014) reports that Croatia and Slovenia are both developed "the new EU Member States". Whereas, relevant internet pages of The Miroslav Krleža Institute of Lexicography (The Miroslav Krleža Institute of LexicographyCroatia.eu) outline that Croatia is still a developing country. The source states that Croatia (Figure 2: Continental and Adriatic Croatia) produces up to $40 \%$ of GDP of the EU average. Whereas West Slovenia produces $83 \%$ and East Slovenia $57 \%$ (Figure 2), respectively (Eurostat, 2019). Tourism covers the fifth part of the total GDP in Croatia (Croatian Bureau of Statistics, 2019; Mitra, 2019). In Slovenia, tourism represents more than $5 \%$ of total GDP (Statistical Office of Republic of Slovenia, 2019; Mitra, 2019).

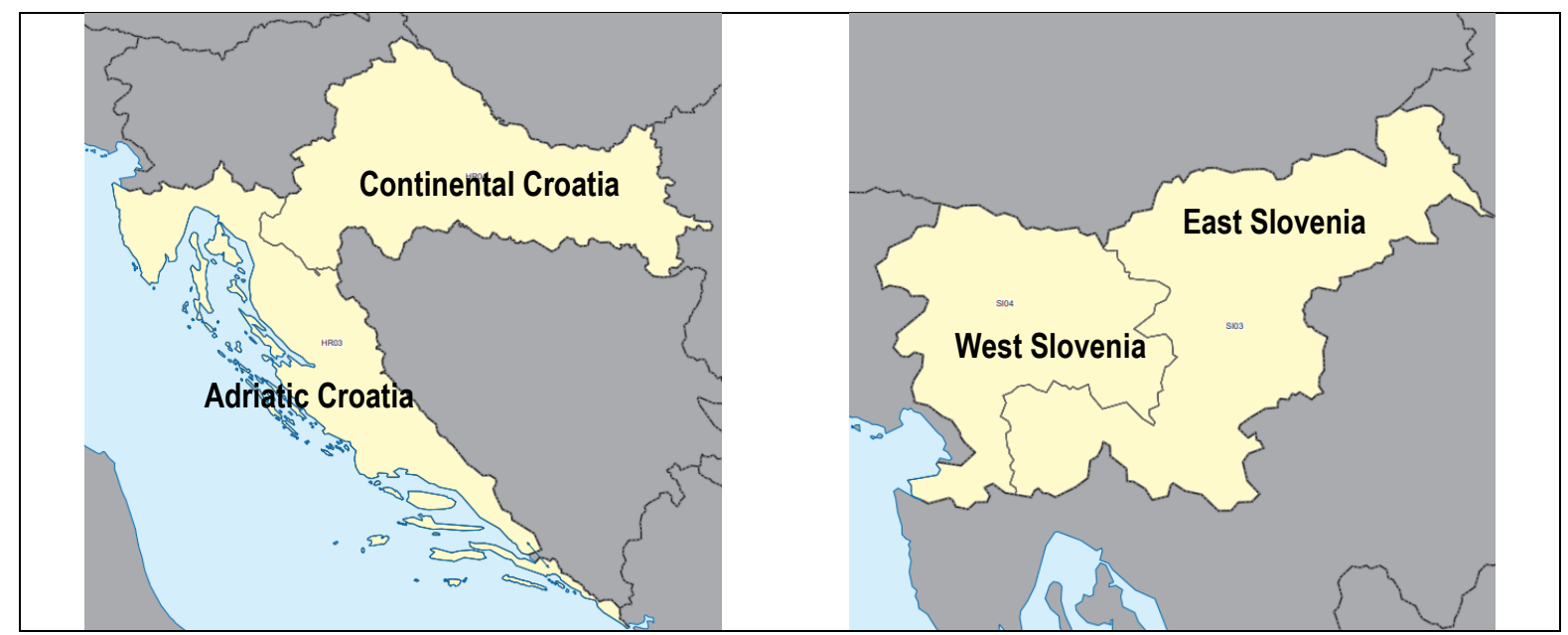

Figure 2 Nomenclature of territorial units for statistics, NUTS 2

Source: Eurostat, 2016

Šoja and Jelić (2016) recognised that Slovenia and Croatia are in the last three places amongst $18 \mathrm{EU}$ countries on specific terms. Those countries have similarities in areas of economic, social, public health, (public) transport, sustainability and global matrix.

Garača (2018) reports that Croatia is the best ranked emerging economy in Southeast Europe in 2018 according to the Inclusive Development Index (IDI) formulated by the World Economic Forum. Slovenia took $19^{\text {th }}$ place on a list of 29 advanced economies. It scored 4.93, just lower than France. In 2017, Slovenia was placed as the $20^{\text {th }}$.

Martín-Martín et al. (2019) follow up on the idea of market economies in a neoclassical model based on the internet services in sharing economy of those unregulated markets (Airbnb, Uber, etc.). Gričar and Bojnec (2019) recognize that the perception of security for a stable market could play an important role because stability (of prices for example) determines competitiveness, prediction and planning.

Galinec et al. (2019) recognise that official statistics is an important issue in EU countries. Novkovska et al. (2018) reviewed that empirical modelling growth is an important value for econometricians and policy makers. For the tourism industry, as well as for other sectors of the service economy, it is of great importance to gain the longest (time) series possible. Therefore, in some aspects, the definition to use monthly, quarterly or yearly data are open for discussion. In a case of national bureaus, the monthly data set could be obtained regarding several limitations where the beginning 
of the time for the data vector is to observe. On the other hand, in both countries, there is no upper limit to the availability of the data. Gričar, et al. (2018) discuss that a suitable source for Adriatic countries is the UN database.

\section{Previous empirical methodology}

The contribution of this paper is to add advanced modelling of the empirical inference based on secondary data for Croatia. In the field of using econometric methods in the tourism industry, Gričar and Bojnec (2019) provide an innovative analysis of unrestricted VAR model on time-series for Slovenia:

$$
{ }_{N}^{l n}\left[\text { OP }^{r} \text { DOS FOS }\right]_{t}^{T}, T=2000: 4, \ldots, 2013: 11 ; N=164,
$$

where $O P^{r}$ is defined as prices become defined at least $\sim I(0)()$ :

$$
O P_{t}^{r}=\ln \left(\frac{O P_{t}}{C P I_{t}}\right)
$$

and structural representation of the cointegrating space in the long term $\left(e c_{t-2}^{2}\right)$ on intervention dummy variables is:

$$
e c_{t-2}^{2} \equiv \ln \left\{\begin{array}{ccc}
-O P_{t}^{r} & F O S_{t} & D^{2} S_{t} \\
-.107 & .014 & -.013 \\
(.147)_{p}(.107)_{p}(.279)_{p}
\end{array}\right\}
$$

for the variables prices for short-stay accommodation $\left(O P_{t}\right)$, domestic tourist overnight stays $\left(D O S_{t}\right)$ and index of foreign tourist overnight stays $\left(F O S_{t}\right)$. The abbreviations are as follows: $e c_{t-2}^{2}$ is the second cointegrated vector, $t$ defines time-series variable, $p$ measures statistical significance, $N$ is number of observations, $T$ obsess analysed time, $r$ captures real-time variable, $\sim I(0)$ describes nearly first order of integration, and $l n$ is the natural logarithm of $x$. Variables are obtained from the Statistical Office of the Republic of Slovenia (SORS). Inflation is treated as a proxy or an external variable. Additionally, Seljak et al. (2018) defined that prices are the most common, widely and empirically used statistical resources.

Econometric modelling refers to the macroeconomic aggregates, such as GDP and prices (Novkovska, et al., 2018, Seljak, et al., 2018) and, in this research particularly, to core tourism development indicators (prices and overnight stays) of two neighbouring EU Member States, Croatia and Slovenia (Table 1 and Table 2). The selection of specific variables is based on the results of commonly used: diagnostic econometric tests, unit root tests, the test of normality of error distribution, as well as decisions about the order of integration of each variable during the modelling process. Gričar et al., (2018) and Gričar and Bojnec (2019) on their empirical and theoretical considerations collect previous empirical researches on the relevant topic stated in the equations given by (1), (2) and (3).

This research aims to re-design the relative econometric models for Croatia, illustrated by using Slovenia as a deterred example defined by Gričar and Bojnec (2019). In both countries there appears to be a lack of adequate empirical and quantitative analysis for tourism industry supported by modern and innovative normality errors distribution tests. Adequate consideration of the results is one of the most important factors in the economy and an important contribution to the scientific study of the tourism industry. Usakli and Kucukergin (2018) disperse the usefulness of the correct specification modelling in the hospitality industry and tourism industry. 
Additionally, some Journals published special issues on modelling that peak for the tourism industry, for example the International Journal of Contemporary Hospitality Management, special issue of November 2018. Liv et al. (2018) confirmed that straight econometric modelling is an important issue for small open economies. The published researches based their predictions on economic growth using the dynamic stochastic general equilibrium framework. XU and Martinez (2018) introduced a statistical technique and namely the longitudinal data as a promotion of more rigorous researches in tourism and hospitality industry management. Park et al. (2018) recognised that there are several methodological steps that were used in tourism.

\section{Research methodology}

This paper seeks to investigate the existence of a long-term relationship between tourism prices and domestic inflation in Croatia. On the basis of quantitative researches, there should be a well-defined and specified methodology.

The main objective of any adopted methodology is to design an accurate and efficient qualitative model that enables significant and credible conclusions and decision-making based on secondary quantitative data. In the paper, based on the research purpose and defined research hypothesis, the time-series research methodology is proposed. It is a research methodology designed for dealing especially with time-series data. The methodology is designed to consider the features of time-series data and their peculiarities (non-stationary in the mean and variance, the existence of unit root, and the normal distribution of the errors). According to Gričar and Bojnec (2016), the proposed methodology is composed of several logically connected phases and namely, descriptive data exploration, data plotting, theoretical model specifying, baseline econometric model estimating, cointegration rank defining, model testing, hypothesis testing and short and long-term cointegration relationships adjusting.

\section{Data}

In order to investigate the existence of a long-term cointegration model between tourism prices and domestic inflation in Croatia, two variables are used: the prices of accommodation services (PAS) and the consumer price index (CPI). Data is collected from the European Union Eurostat database (Eurostat, 2019) and Croatian Bureau of Statistics (Croatian Bureau of Statistics, 2019). Data are monthly and cover the period from February 1998 to September 2019.

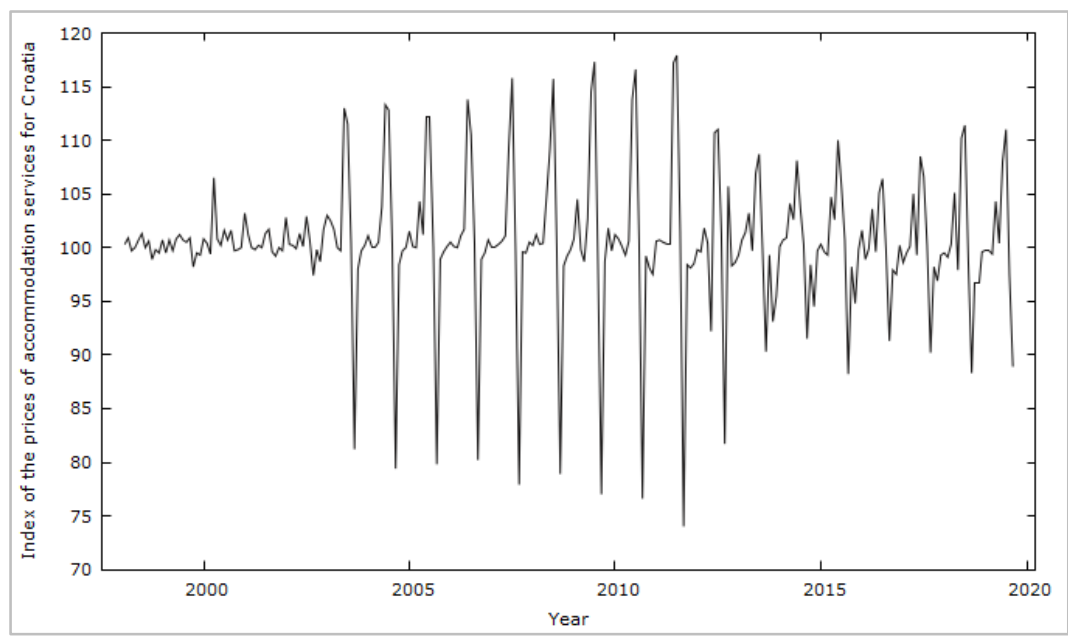

Figure 3 Visual identification of seasonality patterns of PAS

Source: Eurostat, 2019; author's calculations. 
According to the Eurostat PAS covers, first) hotels, motels, inns and similar accommodation services; second) vacation centres, campsites, hostels and similar accommodations, as well as third) accommodation services of other establishments. Figures 3 and 4 depicts the selected variables in the analysed period for Croatia.

The time-series consist of 260 observations that are analysed and are mid-stable. The level data percentage change in relation to the previous month is indexed:

$$
I_{0, t}=x_{0, t}+100 \text {, }
$$

for the data vector:

$$
\stackrel{\operatorname{HR}}{\mathrm{H}(\mathrm{2})}[\mathrm{CPI} P A S]_{t}^{T},
$$

where $T$ is a time period, $t$ is time-series data, $H R$ is abbreviation for Croatia, $I_{0, t}$ marks index of present time-series, $x_{0, t}$ is the observed value at a present time $t$ in percent change to previous month, and $I \sim(2)$ defines variables at nearly a second order of integration. In previous studies, Juselis (2017) and Mladenović, and Jusleius (2002), were concerned that prices are integrated of nearly second order of integration.

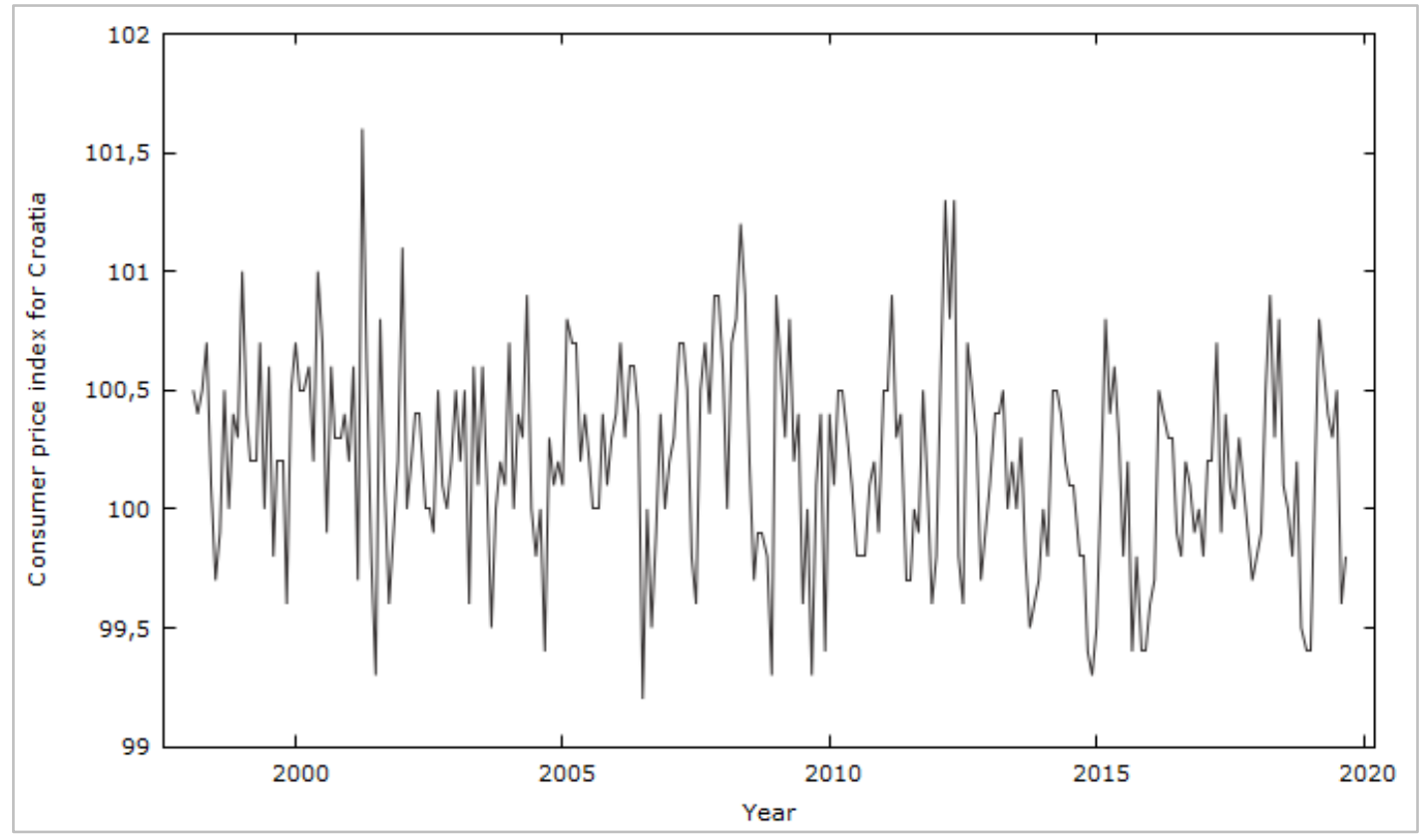

Figure 4 Individual observations of CPI

Source: Eurostat, 2019; author's calculations.

It is understood that prices are the only determinant in the marketing mix that provide income to the company. Aggregated prices at the national or, integrated aggregated level, for example EU, concerns with stochastic trends. The most convenient idea of stationarity of variables derives from the example that if prices traverse its mid-level for more than 10 times, the econometric analysis will find a significant mean change, concluding that the inflation rate is stationary. Regardless, if the econometricians transform inflation in a statistically significant average reversion, time-series considering multi-functional misspecification tests show a result that inflation is a non-stationary variable nearly second order of integration (Juselius, 2009). That the prices are treated stationary in some studies and non-stationary in another might be misleading. There are, therefore, many there are arguments to treat a stochastic trend in unit root as a favourable econometric approximation. 


\section{Empirical settings}

Strong time dependence of macroeconomic data is usually noted by a typical econometric reformulating situated on stochastic processes. In that sense, it is practical to illustrate a stochastic formulation of a typical time-series macroeconomic variable given by (Juselius, 2009):

$$
X=\mathcal{T} \cdot C \cdot S \cdot E,
$$

where, $\mathcal{T}$ is the trend component, $C$ is the cyclical component, $S$ represents the seasonal component and $E$ the irregular component.

Moreover, some other decomposition of the model given by (6) is performed regarding deterministic trend, $t_{d}$, and stochastic trend, $t_{s}$; cyclical component of long term, $c_{l}$, and shorter term, $c_{s}$, as well as a logarithmic transformation (Juselius, 2009):

$$
x=\left(t_{s}+t_{d}\right) \cdot\left(c_{l}+c_{s}\right) \cdot s \cdot e,
$$

to illustrate the intuition of two autonomous shocks $u_{1}$ as a real shock causing $A S$ aggregate supply on institutional policy and $u_{2}$ causing the low demand tourist services causing aggregate demand $A D(10)$.

The long-term stochastic trend in prices is twice accumulated with $A D$ shocks, $\sum \sum u_{1 i}$, and the cyclical component, $c_{l}$, by once accumulated nominal $A D$ shocks, $\sum u_{1 i}$, and once accumulated real $A S$ shocks, $\sum u_{2 i}$, other intervention dummy variables, $g_{i}$, and in (8) the econometric decomposition of the influenced data vector is given (Juselius, 2009):

$$
\left[\begin{array}{l}
\text { pas }_{t} \\
\text { cpi }_{t}
\end{array}\right]=\left[\begin{array}{l}
c_{11} \\
c_{21}
\end{array}\right]\left[\sum \sum u_{1 i}\right]+\left[\begin{array}{l}
d_{11} d_{12} \\
d_{21} d_{22}
\end{array}\right]\left[\begin{array}{l}
\sum u_{1 i} \\
\sum u_{2 i}
\end{array}\right]+\left[\begin{array}{l}
g_{1} \\
g_{2}
\end{array}\right][t]+\text { stat.comp. }
$$

which leads to a better observed data vector and the shocks are:

$$
\Delta y_{t}=v_{t}
$$

where, $v_{t}$ is a permanent or a transitory change and $t$ accounts for linear growth in nominal prices. Long-term and medium-term price homogeneity requires $\left\{c_{11}=\right.$ $c_{21}$, and $\left.d_{11}=d_{21}\right\}$. Typically, when $\left\{g_{1} \neq 0, g_{2} \neq 0\right\}$, the average rate of inflation on nominal PAS in non-zero consistent with stylized certainties in most developed kingdoms or republics.

The equation in (9) suggests that two common stochastic trends affect the level of prices and prices of accommodation services are cointegrated with velocity. Therefore, to obtain homogeneity of $I \sim(0)$ the defined scenario is (Juselius, 2009):

$$
\left[\text { pas }_{t}-c p i_{t}\right]=\left[\begin{array}{ll}
d_{11}-d_{21} & d_{12}-d_{22}
\end{array}\right]\left[\begin{array}{l}
\sum u_{1 i} \\
\sum u_{2 i}
\end{array}\right]+\left[g_{1}-g_{2}\right][t]+\text { stat.comp., }
$$

Based on nominal variables in levels and theoretical explanation in the variables they are logarithmically transformed. According to Juselius (2009) and Brooks (2014) the new variable vector on the subsequent cointegration is:

$$
x_{t}={ }_{H R}^{I \sim(1)}[\operatorname{lncpi} \operatorname{lnpas}]_{t}^{T}, t=1, \ldots T \text {, }
$$


Finally, as defined in equations (1) (2) (3) and (8) the stable procedure is given by a termination vector, as:

$$
{ }_{H R}^{r}\left[\ln \left(\frac{p a s}{c p i}\right)\right]_{t}^{T} T=1998: 2, \ldots, 2019: 9 ; N=260,
$$

where $r$ recognises the real variable, $N$ number of observations (a sample) and $x_{t}$ observed variable. Other notations are mentioned above.

Regarding the data set and (8), the vector measurements are presented in the empirical section based on the following equation usually obtained in the researches:

$$
{ }_{H R}^{r}\left[\Delta \ln \left(\frac{p a s}{c p i}\right)\right]_{t}^{T},
$$

where $\Delta$ is a spread improvement for the first integration on linear growth (9).

\section{Methods}

In this paper, the description of stochastic formulation of the data trend is employed to derive a VAR process, which is the reformulation of data covariance based on the Gaussian (normally i.i.d distributed) errors. The VAR process has often been a popular choice as a description of time-series macroeconomic data. There are many reasons accredited to this: the VAR model is flexible, easy to evaluate and generally fits to macroeconomic data.

The ability to combine long and short-term information in data by leveraging cointegration is possibly the paramount reason why VAR models continue to incur the interest of economists and econometricians. In this paper, the VAR model is used to evaluate the cointegration of PAS (approximated by prices in accommodation services) and CPI (approximated by consumer price indices) in Croatia. With the assumption that the vector given in equation (12) represents the variable set, then the general VAR(p) model can be written as (14):

$$
Y_{t}=\Pi_{1} Y_{t-1}+\Pi_{2} Y_{t-2}+\cdots+\Pi_{p} Y_{t-p}+U_{t} ; \quad U_{t} \sim \text { i.i.d. }(0, \Sigma)
$$

where $Y_{t}$ is dependent variable, $\Pi_{1}$ first lagged matrix of observed time-series $Y_{t-1}$ on lag one, $\Pi_{2}$ second matrix of lag two for observed time-series $Y_{t-2}, \Pi_{p} p$ lagged timeseries matrices, and $U_{t}$ are unknown parameters as sums of squares of the residuals (10).

The inverted VAR model (15) is a useful representation of the stochastic mechanism that represents the data generating process. It describes the seasonal variables as a function of the shocks to the system and the deterministic variables. In contemporary terminology, it is called the common stochastic trends model, in the jargon of Haavelmo (1954) it would have been called the final equations (Juselius, 2015).

\section{Results}

The econometric approach embraces methodological individualism, thus suggesting that economic shocks must be analysed more globally and consider the interaction with other variables resulting from different macroeconomic policies.

In this paper the cointegration of two macroeconomic time-series data are analysed using the cointegrated VAR model. Nominal prices (Figure 3) integrate of 
order two (Table 1). Therefore, the logarithms transformed price variables are used as given in (12). This resulted in variables integrated of order one.

Subsequently, PAS were divided by the CPI as noted in (13). The normality test is more sensitive to skewness than to kurtosis due to smaller variance of skewness. The performing of the Augmented Dickey Fuller test (ADF) $A D F=-0.35^{(-0.01)}$ demonstrated that the time-series in (12) is stationary, and the null-hypothesis of non-stationarity is rejected. On the other hand, more relevant calculations of the ARCH test for autocorrelation and the Jarque-Bera test for normality confirmed that the time-series in its form (8) provides a non-normal time-series, which is not a relevant issue for further analysis. The null hypothesis that there is normality in the model (13) is rejected primarily because of non-normality in real PAS and CPI equation.

Whilst possibly useful, such conventional facts are nonetheless too coarse and can even be misleading when data is non-stationary. This is because correlation coefficients and mean growth rates are only well defined for stationary data, but not non-stationary. This confirms the presence of unit root and intervention dummy variables that influence the mean of the integrated process and the stability of the model. Therefore, in present research, seasonal dummy variables and a constant term are implemented. In table, 1 some descriptive statistics for the analysed variables are summarized.

Table 1 Summary statistics

\begin{tabular}{|l|r|r|r|r|r|}
\hline \multicolumn{1}{|c|}{ Time-series } & \multicolumn{1}{|c|}{ Min } & Max & \multicolumn{1}{c|}{ SD } & \multicolumn{1}{c|}{ Skewness } & \multicolumn{1}{c|}{ Kurtosis } \\
\hline CPI & 99.20 & 101.60 & 0.42 & 0.09 & -0.07 \\
PAS & 74.00 & 117.90 & 6.42 & -0.89 & 4.51 \\
Model (12) & 0.74 & 1.18 & 0.06 & -0.80 & 4.53 \\
Model (13) & -0.27 & 0.24 & 0.07 & -0.18 & 2.52 \\
\hline & & & & ARCH test & Normality test \\
\hline Model (13) & \multicolumn{7}{r}{} & & $84.34(0.00)$ & $69.81^{(0.00)}$ \\
\hline
\end{tabular}

Note: $(y . x)-p$-values in brackets.

Source: Eurostat, 2019; author's calculations.

In order to understand the price homogeneity in long-term and short-term relations in the tourism industry, a model with all basic assumptions as testable hypotheses on the VAR model was formulated. In empirical research regarding the tourism industry, it is important to consider theory consistent VAR scenario. Such methods are conducive to having theoretically correct statistical models for empirically credible results for prediction of future movements in tourism. Figure 5 shows transformed variable (13) in a real value. Data vector is unified of nearly first order of integration.

The purpose of the research is to recognise that the specification of the model is of crucial importance and a visual inspection could be one leading signal to conduct researches in order to design adequate econometric models. In the nuanced model the intervention is easier to observe in $\Delta x_{t}(8),(13)$ like in the $x_{t}(7),(11),(12)$. Thus, a preliminary decision to model a shock intervention, for example, with a trend dummy, can be made by examining the logarithm or integrated process. Figure 5 demonstrates that the transformed variable is highly volatile and therefore correlated to several impulses and other dummy variables. 


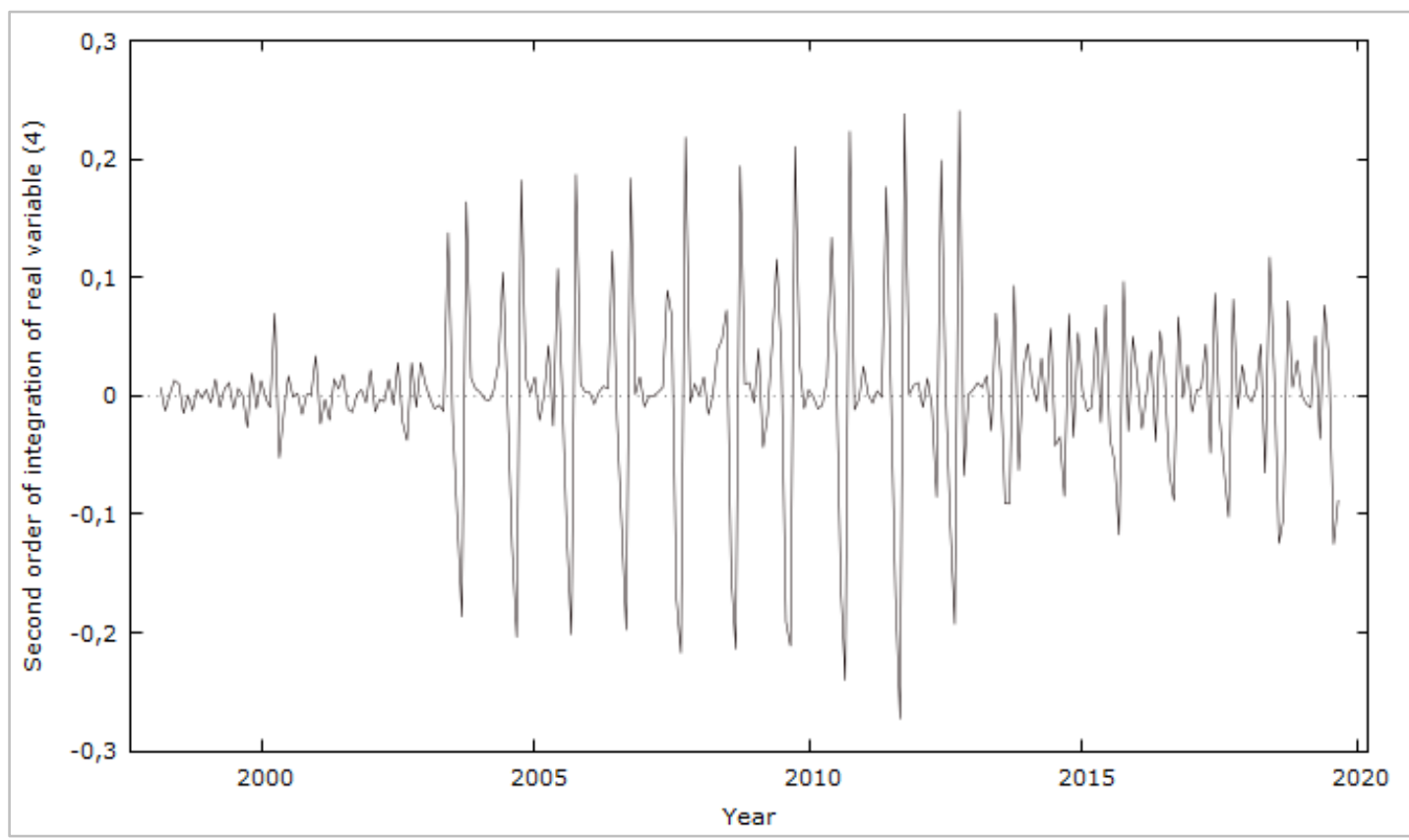

Figure 5 Croatian prices of accommodation services in integrated real values (13) Source: Eurostat, 2019; author's calculations.

The analysis for Croatia found that tourism sub-industry (lodging) has had several obstacles between 2003 - 2013, including the most relevant recent economic crisis (Figure 2). This could be a pertinent prediction for the next volatility period, which, regarding Figure 5, started in 2018. The results are similar compared to the Slovenian ones during the crisis period.

Using intervention dummy variables (Figure 6) to rate for abnormalities as meanshifts, permanent blips, and transitory shocks, the VAR model (14) is redeveloped as:

$$
\Delta x_{t}=\Gamma_{1} \Delta x_{t-1}+\alpha \cdot \beta^{\prime} x_{t-1}+\phi_{p} \cdot D_{p, t}+\phi_{s} \cdot D_{s, t}+\mu_{0}+\varepsilon_{t}, \varepsilon_{t} \sim N I(0, \Omega), t=1, \ldots T,
$$

where $D_{p, t}$ is a $d_{1} \times 1$ vector of permanent blip dummy variables $(\ldots, 0,0,1,0,0, \ldots)$, and $D_{s, t}$ is a $d_{2} \times 1$ vector of mean-shift dummy variables $(\ldots, 0,0,0,1,1,1, \ldots), \sim$ denotes distributed, $I$ is a shorthand notation for independent, $N$ for normal, $\Omega$ time-varying variance, $\beta^{\prime} x_{t-1}$ cointegration relations of matrix $\Pi$ on restrictions of $\alpha$ eigenvectors, and $\Gamma_{1} \Delta x_{t-1}$ is a $\operatorname{VAR}(1)$ matrix with regressor coefficients for the short-term. Because the VAR model holds differences and levels of time-series variable, the role of the dummy variable is more complex than in the conventional regression model (Juselius, 2009).

Consistent with the results of the VAR model, a new VAR (the VAR(2)) model with permanent dummy variables is re-estimated. In the new VAR(2) model, seasonal dummy variables are included as the $\phi_{t r} \cdot D_{t r}$ is a $d_{3} \times 1$ vector of shock dummy variables $(\ldots, 0,0,1,-1,0,0, \ldots)$ in (15) resulting in:

$$
x_{t}=\Gamma_{1} \Delta x_{t-1}+\alpha \cdot \beta^{\prime} x_{t-1}+\phi_{p} \cdot D_{p, t}+\phi_{s} \cdot D_{s, t}+\phi_{t r} \cdot D_{t r}+\mu_{0}+\varepsilon_{t},
$$

and it is for simplicity, assumed that $\Gamma_{1}=0$, the cointegrated VAR model can now be signed as: 


$$
\begin{gathered}
\Delta x_{t}=\left[\left(\frac{p a s}{c p i}\right)\right]=[-0.06]\left[\left\{-0.32 \cdot p s_{t}-c p i_{t}\right\}_{t-1}\left\{-0.37 \cdot p^{2} s_{t}-c p i_{t}\right\}_{t-2}\right]+\left[\mu_{1}\right]+ \\
{\left[\begin{array}{c}
-0.49_{t r, 01} \\
-0.55_{t r, 02} \\
-0.61_{t r, 03} \\
-0.46_{t r, 04} \\
-0.68_{t r, 05} \\
0.19_{t r, 06} \\
-0.30_{t r, 07} \\
-0.11_{t r, 08} \\
-0.23_{t r, 09} \\
-0.00_{t r, 10} \\
-0.07_{t r, 11} \\
0.00_{g, s}
\end{array}\right]+\phi \cdot D_{t},}
\end{gathered}
$$

$F$-test on all regressors: $F(13,243)=45.29, R^{2}=0.69, D-W=2.29, g_{S}=0$ and $\phi \neq 0$, where specification test for the unrestricted $V A R(2)$ model with seasonal dummies is in Table 2 and $\mu_{1}$ is the conditional mean of VAR, $\phi$ is autoregressive model parameters and $D-W$ is Durbin Watson statistics. Those accumulated in (8), defined by data set $g_{s}=0$ in (17) defines that trend $D_{t}$ do not have any empirical solution in an economy in a long or medium-term.

Table 2 Specification test of unrestricted VAR(2) model with seasonal dummies

\begin{tabular}{|l|l|}
\hline \multicolumn{1}{|c|}{ Test } & \multicolumn{1}{|c|}{ Result } \\
\hline Residual Autocorrelations & $47.06(0.00)$ \\
Normality & $77.07(0.00)$ \\
\hline
\end{tabular}

Note: $(y \cdot x x)-p$-values in brackets.

Source: author's calculations.

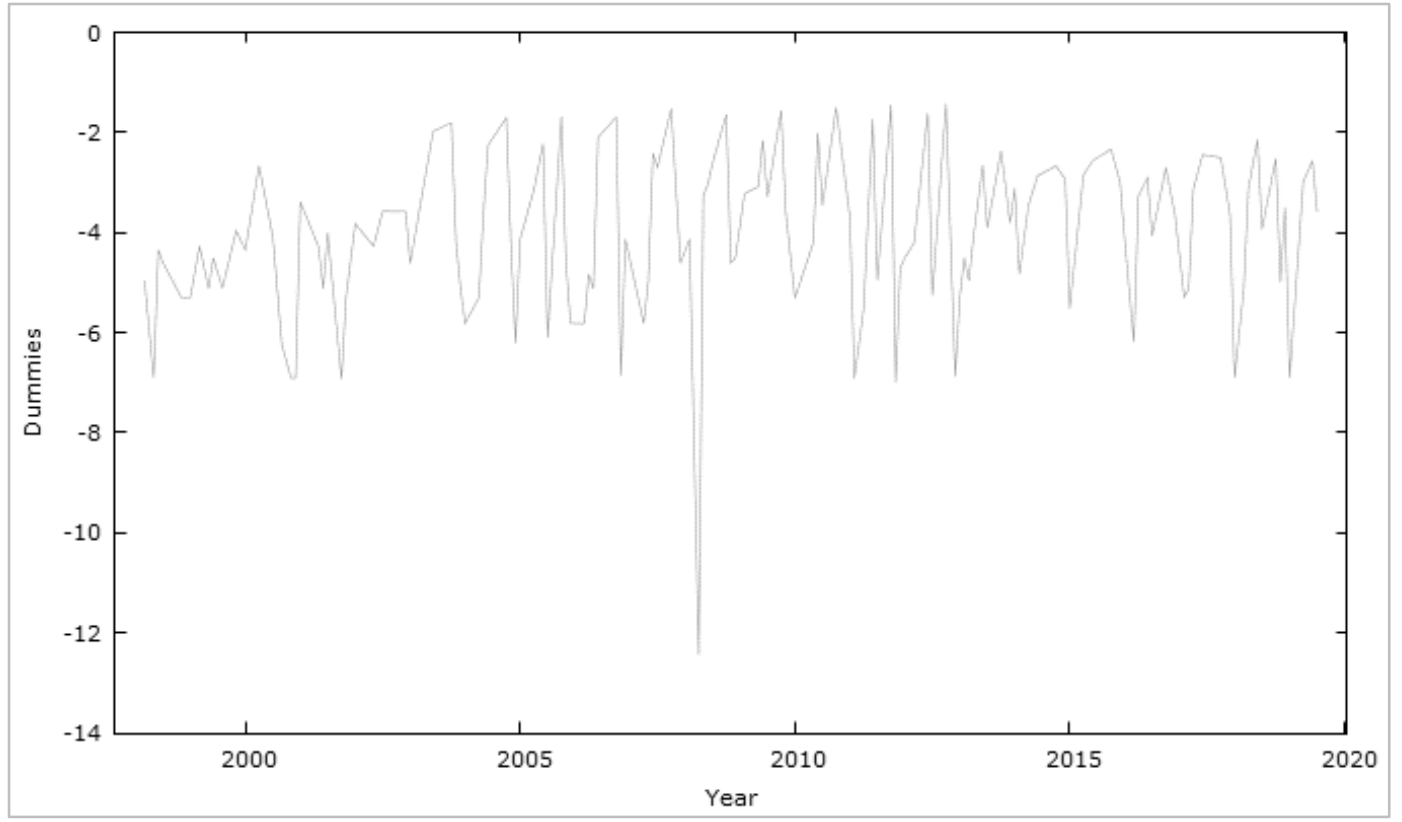

Figure 6 Events and shocks in a VAR model (15)

Source: Eurostat, 2019; author's calculations.

The long and persistent deviations from the long-run mean values shown in Figure 6 indicate the existence of self-boosting processes in the system. Such an action is likely 
to be a combination of an increase in mean errors (regeneration) and error-correcting actions (stagnation), or in fitting one polynomial cointegration relation. This conclusion is reinforced by similar results based on Danish-German data (Juselius 2009, chap. 21).

The results confirm the hypotheses $\mathrm{H}_{1}$ where tourism prices (prices of non-tradable goods) are intended for a domestic market (Croatian inflation) relation. Hence, tourism prices are assumed to be treated by domestic (Croatian) speculations. These results are in correlation to Juselius (2017a) and Phelps (1994) that constant mark-up pricing replaces (AS shock) customer market pricing (AD shock). Evidence of a nonstable pricing share co-moving has been found in Juselius (2009).

Seasonal dummies do not provide a normal model; alternatively, they provide a model without autocorrelation on any lags. Therefore, Figure 6 should be further analysed mostly on a vector of mean-shift dummy variables, such as the Easter Period, New Year Period, entering the EU integration and other outliers that are timedependent.

The properties of residuals from the estimated VAR(2) model with above-mentioned dummy variables could improve the unrestricted model. The VAR(2) model should not have autocorrelations, no ARHC effect or non-normality. With Lag Reduction Tests (LR) one could decide for $\mathrm{k}=2$ lags (Kivedal, 2014).

The research offers strong evidence of how basic treatments, based on a theoretical model, can be transformed into the test hypotheses about the order of integration and cointegration of selected time-series and their relationships. The sense of the theoretically consistent CVAR scenario is that describes empirical regularities expected in the data if the long-term properties of the theoretical model are empirically relevant. The process is exhibited for tourism prices in Croatia and Slovenia.

The results provide significant support for the information-less-incomplete knowledge model. Two comparable models (one for Slovenia and one for Croatia) seem particularly capable of explaining long-term and persistent fluctuations in nominal prices.

As prices are amongst the most important determinant of real economy and the only determinant in the marketing mix that provide income, results indicate the importance of understanding the root cause of long persistent movements that are usually developed over time and to anticipate the recent financial and economic crisis as disregarding existing models. Without this understanding, behaviour in prices is likely to create high volatilities and crises that will affect the macroeconomics and subsequent political turmoil. Nonetheless, this paper highlighted the importance of understanding the reflexive relationship between different sectors of any national economy.

\section{Conclusion}

In the paper, the relevance of econometric modelling using secondary data is taken into account. First, based on two time-series variables the importance of well-defined modelling in tourism sub-industry (e.g. lodging) was researched for Croatia. Several patterns are important to measure the volatility, normality and other miss specifications of the model that are found in the secondary data and not to be satisfied with the ADF test. Second, theoretical and empirical econometric models for Croatia were supported by a comparative analysis with previous results for Slovenia. In the period 2003-2013, the Croatian tourist industry provided several swings concerning economic growth and the following crisis.

Therefore, this paper gains significant relevance for researchers, managers and all stakeholders involved in the tourism industry. Several intervention dummy variables should be included as outliers denoting both crisis and declining times in the prices. 
Subordinated to these results, the hypotheses are generally confirmed. A general framework for translating major predictions from the theoretical model into testable hypotheses within VAR model is suggested. Results confirmed that the variable PAS is related to the season in the short-term. Additionally, Figure 6 proposed to obtain and release several mean-shift dummy variables, such as the Easter and New Year period and other outliers that are time-dependent to determine pulling and pushing effects.

The analysis of the research plays important part towards literature on the price science that is important for each business as income and aggregated for each national economy as tax on price. Nonetheless, well-defined econometric model could predict future in economic boundaries in tourism and proving the results (robustness) generated on cointegration.

In future researches, additional recognition of structural breaks with intervention dummy variables should be emphasized. An idea for a specified unrestricted VAR model described by the data with two lags and some ranks with variables of domestic and foreign tourist arrivals are to be added. That could represent the pulling effects, and common stochastic trends, which pushes the process. Furthermore, by using Lagrange Multiplier testing it could be indicated that the model does not display autocorrelation, no ARCH effect, and normality of residuals, what could be found out through the Jarque Bera test. The skewness of the model should be in a range of 0 and Kurtosis in a range of 3 , suggesting that the model is normally distributed. The lack of any weak exogenous variables should be determined.

The idea of further research methodology lies in the panel cointegration, whereas the development for panel cointegration is still in its infancy as well as in modelling processes, models and applied panel methods.

\section{References}

1. Atkinson, A. B., Brandolini, A. (2001). Promise and pitfalls in the use of secondary data-sets: Income Inequality in OECD countries as a case study. Journal of Economic Literature, Vol. 39, No. 3, pp. 771-799.

2. Brooks, C. (2014). Introductory econometrics for finance. Cambridge University Press, Cambridge.

3. Croatian Bureau of Statistics (2019). Statistical Databases. Available at https://www.dzs.hr/ default_e.htm [6 September 2019].

4. The Miroslav Krleža Institute of Lexicography (2019). Economic transition. Available at https://croatia.eu/article.php?id=31 \&lang=2 [6 September 2019].

5. Eurostat (2016). NUTS - Nomenclature of territorial units for statistics. Available at https://ec.europa.eu/eurostat/web/nuts/background [7 September 2019].

6. Eurostat (2019). Gross domestic product (GDP) at current market prices by NUTS 2 regions. Available at https://ec.europa.eu/eurostat/web/products-datasets/-/nama_10r_2gdp [7 September 2019].

7. Galinec, D., Vuglar, J., Cvrtila, D. (2019). Residential property price index in Croatia: from experimental to official statistics. Croatian Review of Economic, Business and Social Statistics, Vol. 5, No. 1, pp. 33-42.

8. Garača, M. (2018). Croatia top emerging economy in SEE. World Economic Forum, Business Intelligence for Southeast Europe, Sofia.

9. Gričar, S., Bojnec, Š. (2016). Aplikacija metodologije časovnih serij na primeru turističnih cen. University of Primorska Press, Koper.

10.Gričar, S., Bojnec, Š. (2018). Tourism price causalities: Case of an Adriatic country. International Journal of Tourism Research, Vol. 20, No. 1, pp. 82-87.

11.Gričar, S., Bojnec, Š. (2019). Prices of short-stay accommodation: time series of a eurozone country. International Journal of Contemporary Hospitality Management, Vol. 31 No. 12, pp. 4500-4519. 
12.Gričar, S., Bojnec, Š., Karadžić, V., Backović Vulić, T. (2018). Tourism in Montenegro and Slovenia: breaks in time series. In International symposium on business and economics, Metin, T. C. et al. (Eds.), Global Science Institute, Podgorica, pp. 18-26.

13. Gričar, S., Šugar, V., Bojnec, Š. (2019). Small and medium enterprises led-growth in two Adriatic countries: Granger causality approach. Economic Research-Ekonomska Istraživanja, Vol. 32, No. 1, pp. 2161-2179.

14. Haavelmo, T., (1954). Structural models and econometrics. Unpublished paper presented at the Econometric Society Meeting, Stockholm.

15. Hand, D. J. (2018). Statistical challenges of administrative and transaction data. Royal Statistical Society, Vol. 181, No. 3, pp. 555-605.

16.Janković Šoja, S., Bucalo Jelić, D. (2016). Indicators of sustainable development performance: Case study of European Union countries. Croatian Review of Economic, Business and Social Statistics, Vol. 2, No. 2, pp. 1-9.

17.Juselius, K., (2009). The cointegrated VAR model: methodology and applications. Oxford University Press, Oxford.

18.Juselius, K. (2015). Haavelmos probability approach and the cointegrated VAR. Econometric Theory, Vol. 31, No. 2, pp. 213-232.

19. Juselius, K. (2017). Recent developments in cointegration. Econometrics, Vol. 6, No. 1.

20.Juselius, K. (2017a). Using a theory-consistent CVAR scenario to test an exchange rate model based on imperfect knowledge. Econometrics, Vol. 5, No. 30, pp. 1-20.

21. Kivedal, B. (2014). A DSGE model with housing in the cointegrated VAR framework. Empirical Economics, Vol. 47, No. 3, pp. 853-880.

22.Liu, A., Song, H., Blake, A. (2018). Modelling productivity shocks and economic growth using the Bayesian dynamic stochastic general equilibrium approach. International Journal of Contemporary Hospitality Management, Vol. 30, No. 11, pp. 3229-3249.

23.Martín-Martín, J. M., Ostos-Rey, M. S., Salinas-Fernández, J. A. (2019). Why regulation is needed in emerging markets in the tourism sector. American Journal of Economics and Sociology, Vol. 78, No. 1, pp. 225-254.

24. Mitra, S. M. (2019). Is tourism-led growth hypothesis still valid? International Journal of Tourism Research, Vol. 21, No. 5, pp. 615-624.

25.Mladenović, Z., Juselius, K. (2002). High inflation, hyperinflation and explosive roots: The case of Yugoslavia. University of Copenhagen, Department of Economics, Copenhagen, Working Paper.

26.Mukherjee, C., White, H., Wuyts, M. (1998). Econometrics and data analysis for developing countries. Routledge, New York.

27.Novkovska, B., Palić, I., Hodžić, S. (2018). Editorial for the special issue: "Advances in statistical modelling for economic Policy-Making" in Croatian Review of Economic, Business and Social Statistics. Croatian Review of Economic, Business and Social Statistics, Vol. 4, No. 2, pp. 1-4.

28.Park, E., Chae, B., Jwon, J. (2018). Toward understanding the topical structure of hospitality literature. International Journal of Contemporary Hospitality Management, Vol. 30, No. 11 , pp. 3386-3411.

29.Phelps, E. S. (1994). Structural slumps. Princeton University Press, Princeton.

30.Seljak, R., Bregar, L., Colić, S., Dozet, M. (2018). Probabilistic sampling strategy as a means of improving quality of price indices. Croatian Review of Economic, Business and Social Statistics, Vol. 4, No. 2, pp. 35-46.

31.Senbeto, D. L., Hon, A. H. Y. (2019). A dualistic model of tourism seasonality: Approachavoidance and regularity focus theories. Journal of Hospitality and Tourism Research, Vol. 43, No. 5, pp. 734-753.

32.Statistical Office of Republic of Slovenia (2019). SISTAT. Available at: https://pxweb. stat.si/SiStatDb/pxweb/sl/20_ekonomsko/20_Ekonomsko_03_nacionalni_racuni_35 _03808_ekonom_rac_turizem/0380845S.px/table/tableViewLayout2/ [30 August 2018].

33. United Nations (2014). Country classification. United Nations, New York.

34.Usakli, A., Kucukergin, K. G. (2018). Using partial least squares structural equation modeling in hospitality and tourism. International Journal of Contemporary Hospitality Management, Vol. 30, No. 11 , pp. 3462-3512. 
35.Xu, S., Martinez, L. (2018). Applications of latent growth curve modeling: a research agenda for hospitality management. International Journal of Contemporary Hospitality Management, Vol. 30, No. 11, pp. 3268-3286.

\section{About the authors}

Sergej Gričar, is assistant professor at the University of Novo mesto Faculty of Economics and Informatics, Slovenia. Sergej gained a Ph.D. in management from the University of Primorska, Faculty of Management, Slovenia. He was a post-doctoral research fellow at the University of Montenegro, Faculty of Economics, Podgorica, Montenegro, coordinated by University of Ghent, Belgium. Sergej has published in leading journals: International Journal of Contemporary Hospitality Management, International Journal of Tourism Research, Eastern European Economics and Economic Research, amongst others. In 2013, Sergej received "Srečko Kosovel" recognition with interests in Time-series unit-root econometrics and applied research in tourism industry. Sergej works in the Swedish tourism industry. Sergej is finishing "lang syne" studies at the University of Rijeka, Faculty of Tourism and Hospitality Management. Sergej can be contacted at sergej.gricar@gmail.com.

Tea Baldigara is a full professor and head of Institute for Finance at the Faculty of Tourism and Hospitality Management, University of Rijeka, Croatia. She currently teaches Applied Econometrics, Quantitative Methods in Tourism and Hotel Industry Decision-Making, Quantitative Methods in Business Administration and Statistical Process Control. Tea Baldigara received her MSc degree from the University of Rijeka, Faculty of Economics in 1999 and her Ph.D. from the University of Rijeka, Faculty of Tourism and Hospitality Management in 2004. Her areas of research include quantitative methods in tourism demand modelling and forecasting. Tea is the author of 2 books and more than 60 scientific papers. With more than 20 years of teaching and researching experience, she took part in several training programmes, was awarded various scholarships and took part in the Erasmus teaching staff mobility programmes. Tea can be contacted at teab@fthm.hr. 